\title{
Does exposure to coal dust prevent or cause lung cancer?
}

\author{
Leslie T Stayner, Judith M Graber
}

Research published in this journal and elsewhere has demonstrated an increased risk of pneumoconiosis and more recently chronic obstructive pulmonary disease among coal miners. Despite this extensive research base, many puzzles remain such as the deficit of lung cancer reported in many studies of coal miners. These findings are surprising since in addition to coal dust, miners are exposed to other substances that are widely recognised as causing respiratory cancer in humans, most notably silica, ${ }^{1}$ but also diesel exhaust and radon gas. We have chosen for this editorial two landmark papers from the journal archives that addressed this as yet unresolved issue.

In his 1955 article, Primary lung cancer in South Wales coal-workers with pneumoconiosis, ${ }^{2}$ James described the autopsy findings of approximately 1800 coal miners and 1500 non-miners who died in South Wales between 1947 and 1952. Lung cancer was found to be less common in coal miners $(3.3 \%)$ than in non-miners $(5.4 \%)$. Furthermore, the proportion of lung cancers appeared to be inversely related to the severity of pulmonary disease in the coal miners, being $5.1 \%$ among individuals with simple pneumoconiosis and only $1.4 \%$ among individuals with progressive massive fibrosis. Based on his study and previous autopsy studies with similar findings, ${ }^{3-5}$ James concluded that the findings "do not suggest that inhaled coal dust is carcinogenic".

Goldman in his 1965 article, ${ }^{6}$ Mortality of coal-miners from carcinoma of the lung, presented a review of findings from several published studies and unreported investigations that supported the hypothesis that "mortality from cancer of the lung is appreciably lower for coal-miners than for other men of similar age". He gives credit for the initial discovery to Kennaway and

Division of Epidemiology and Biostatistics, School of Public Health, University of Illinois at Chicago, Chicago, Illinois, USA

Correspondence to Leslie T Stayner, Division of Epidemiology and Biostatistics, School of Public Health, University of Illinois at Chicago M/C 923, 1603 West Taylor Street, Chicago, IL 60612-4392, USA;

istayner@uic.edu
Kennaway who reported in 1936 that lung cancer mortality among coal miners was approximately $50 \%$ lower than among men in other occupations in England and Wales. ${ }^{7}$ These findings were corroborated by the 1958 Registrar General's decennial report on occupational mortality, ${ }^{9}$ which reported that the standardised mortality ratio (SMR) for lung cancer in coal miners in England and Wales was 71. ${ }^{\mathrm{i}}$ Goldman also cites as evidence of a lung cancer deficit the aforementioned autopsy studies and the landmark study by Sir Richard Doll of nickel workers, which incidentally examined mortality in coal miners and reported an approximately $50 \%$ deficit in proportionate mortality from lung cancer. ${ }^{3}$ Goldman presented new findings from a study of coal miners using data from the National Coal Board. A deficit in lung cancer (SMR 74) was found which was lower among underground coal miners (SMR 70) than among surface miners (SMR 92). Finally, Goldman observed that lung cancer mortality was lower in coal mining communities than in non-coal mining communities in Wales.

Goldman presented a very thoughtful discussion of potential explanations for the deficit of lung cancer mortality in coal miners, including differential smoking rates among workers, competing risks, misdiagnosis bias and possible differential exposures of workers to outdoor pollutants. None provided an adequate explanation. For smoking Goldman noted that the percentage of smokers among coal miners was reported to be somewhat higher than that among other workers in England and Wales. He noted that competing risks from accidents and pneumoconiosis might explain the findings from the autopsy or proportionate mortality studies but was unlikely to provide an explanation for the findings from the SMR studies. Lung cancer might be under-diagnosed in the presence of severe pneumoconiosis, but Goldman felt

iNote these authors used the convention of multiplying the ratio of the observed to expected number of deaths by 100 . This convention will be used consistently in this editorial. this was probably offset by the higher autopsy rate among coal miners compared to non-miners. Finally, Goldman argued that the hypothesis that the deficit in lung cancer might be explained by air pollution being lower in the rural areas where the coalmines were located was not supported by the fact that the wives of coal miners did not have such dramatically low lung cancer rates as the miners.

Based on his review, Goldman suggested that it might in fact be the case that "the inhalation of coal-dust antagonises the induction of pulmonary malignant change". He suggested that the facts that lung cancer mortality was lower in underground miners than among surface miners and that the risk of lung cancer decreased with increasing degree of pneumoconiosis provided additional support for this hypothesis. Interestingly, the hypothesis that coal dust may actually prevent lung cancer is consistent with recent experimental evidence that exposure to coal dust may inhibit the expression and activity of CYP1A1 in the lung, which is involved in the metabolism of polycyclic aromatic hydrocarbons in cigarette smoke to reactive intermediates believed to be involved in carcinogenesis. ${ }^{10}$

How has the hypothesis that lung cancer mortality is decreased among coal miners held up since the seminal publications by James and Goldman? While most cohort studies published since that time have shown a deficit in lung cancer among coal miners, ${ }^{11-16}$ there have been some notable exceptions. ${ }^{17-21}$ A small to moderate excess of lung cancer has also been reported in several population based case-control studies. ${ }^{22-24}$ Particularly illuminating are the findings from the most recent follow-up of the US and British coal miner cohorts, which both show the deficit disappearing with additional follow-up. In the most recent findings from the US cohort, lung cancer mortality was slightly higher than expected (SMR 107, 95\% CI 95 to 119), ${ }^{20}$ in contrast with the significant deficit in the previous update of that study (SMR 77, 95\% CI 60 to 99). ${ }^{14}$ Similarly, Miller et al recently reported that lung cancer mortality was close to expected (SMR 98, $95 \%$ CI 93 to 105) in the British cohort and that there was a significant excess of lung cancer (SMR 118, 95\% CI 105 to 128) in the most recent follow-up period. ${ }^{21}$ The findings from these two studies strongly suggest that the previously reported deficit in lung cancer mortality may be explained by a particularly strong example of the healthy worker effect (HWE). The 
HWE bias, which is in part related to the initial hiring of workers who are healthier than the general population, has long been recognised as disappearing with extended follow-up of cohorts. ${ }^{25}$

Miller suggests that the excess of lung cancer in the most recent follow-up period of his cohort might also be explained by the fact that miners were not allowed to smoke while underground, and that this protective effect was removed after the mines were closed. This is plausible, but it also raises the question as to whether there could be a true excess of lung cancer among coal miners that has been masked by the HWE and the prohibition of smoking in coalmines? The lack of evidence for an exposure-response relationship between coal dust and lung cancer in the British study argues against this conjecture, particularly since such a relationship was observed for silica. These analyses largely avoid the bias related to the HWE since they are internal analyses that do not rely on comparisons with the general population. However, these analyses do not fully control for the potential bias related to cigarette smoking, since workers with long duration of employment and high cumulative exposure would also have been prevented from smoking during the workday for long periods of time. Although smoking was controlled for in the British study, it was based on smoking at the time of entry and thus there was no control for the reduction in smoking that resulted from employment in the mines.

By now many readers of this editorial may be asking why they should care about this issue. Coal mining is an old industry and the hazards associated with coal mining have been exhaustively studied. First, coal is still a major industry in the USA and other parts of the world; production has actually been increased in the USA over the last decade. ${ }^{26}$ Second, the hazards associated with coal dust exposure have not disappeared, and in fact coal worker's pneumoconiosis has been increasing in the USA. ${ }^{27}$ Admittedly, the risk of lung cancer is probably not the greatest concern for these miners given their high risk of non-malignant respira- tory diseases and accidents. However, coal dust serves as a model for understanding the mechanistic basis of the carcinogenicity of other insoluble particulates. The lack of evidence of a respiratory cancer risk in coal miners may be seen as a reason to dismiss the relevance for humans of the findings from toxicological studies of an increase in lung tumours in animals exposed to other insoluble particulates such as carbon black and diesel exhaust. ${ }^{29}$

Resolution of this question will not be easy and will require studies of coal miners that include detailed measurements of coal dust and silica, control of biases related to the HWE, and perhaps, most importantly, careful control of confounding by smoking. Regarding smoking, one approach that may be useful for future analyses is to examine the exposureresponse relationship between coal dust and lung cancer among non-smokers.

\section{Competing interests None.}

Provenance and peer review Commissioned; not externally peer reviewed.

Accepted 2 August 2010

Published Online First 15 October 2010

Occup Environ Med 2011;68:167-168.

doi:10.1136/oem.2009.048223

\section{REFERENCES}

1. International Agency for Research on Cancer (IARC). Silica. Volume 68, Lyon, France: IARC 1997.

2. James WR. Primary lung cancer in South Wales coal-workers with pneumoconiosis. $\mathrm{Br} \mathrm{J}$ Ind Med 1955; 12:87-91.

3. Doll R. Cancer of the lung and nose in nickel workers. Br J Ind Med 1958;15:217-23.

4. Gooding CG. Pneumoconiosis in South Wales anthracite miners. Lancet 1946;2:891-6.

5. McVittie JC. Pneumoconiosis in coal miners. Postgrad Med J 1949:25:618-31.

6. Goldman KP. Mortality of coal-miners from carcinoma of the lung. Br J Ind Med 1965;22:72-7.

7. Kennaway EL, Kennaway NM. A study of the incidence of cancer of the lung and larynx. $J$ Hyg (Lond) 1936;36:236-67.

8. Kennaway EL, Kennaway NM. A further study of the incidence of cancer of the lung and larynx. Br J Cancer 1947;1:260-98.

9. Registrar General's Decennial Supplement. Occupational Mortality. Part II, Volume 1. England and Wales: HMSO London 1951(1958): 9,18, 35 and 96

10. Ghanem MM, Porter D, Battelli LA, et al. Respirable coal dust particles modify cytochrome P4501A1
(CYP1A1) expression in rat alveolar cells. Am J Respir Cell Mol Biol 2004;31:171-83.

11. Atuhaire LK, Campbell MJ, Cochrane AL, et al. Specific causes of death in miners and ex-miners of the Rhondda Fach 1950-80. Br J Ind Med 1986:43:497-9.

12. Liddell FDK. Mortality of British coalminers in 1961 Br J Ind Med 1973:30:15-24.

13. Costello J, Ortmeyer CE, Morgan WKC. Mortality from lung cancer in US coalminers. Am J Public Health 1974;64:222-4.

14. Kuempel ED, Stayner LT, Attfield MD, et al. Exposure-response analysis of mortality among coal miners in the United States. Am J Ind Med 1995;28:167-84.

15. Morfeld P, Lampert K, Ziegler $\mathrm{H}$, et al. Coal mine dust exposure and cancer mortality in German coal miners. Appl Occup Environ Hyg 1997;12:909-14.

16. Morfeld P, Lampert K, Emmerich $\mathrm{M}$, et al. Dust exposure, pneumoconiosis and lung cancer; an epidemiological study in the Saar hard coal mining. Zbl Arbeitsmed 2002;52:382-97.

17. Enterline PE. A review of mortality data for American coalminers. Ann NY Acad Sci 1972;200:260-72.

18. Rockette HE. Cause specific mortality of coal miners. J Occup Med 1977;19:795-801.

19. Miyazaki M, Une H. Risk of lung cancer among Japanese coal miners on hazard risk and interaction between smoking and coal mining. J Occup Health 2001;43:225-30.

20. Attfield MD, Kuempel ED. Mortality among U.S. underground coal miners: a 23-year follow-up. Am J Ind Med 2008:51:231-45.

21. Miller BG, Maccalman L. Cause-specific mortality in British coal workers and exposure to respirable dust and quartz. Occup Environ Med 2010;67:270-6.

22. Swanson GM, Lin CS, Burns PB. Diversity in the association between occupation and lung cancer among black and white men. Cancer Epidemiol Biomarkers Prev 1993;2:313-20.

23. Siemiatyckl J. Risk factors for cancer in the workplace. Boca Raton, FL: CRC Press, 1991.

24. Morabia A, Markowitz S, Garibaldi K, et al. Lung cancer and occupation: results of a multicentre case-control study. Br J Ind Med 1992;49:721-7.

25. Fox AJ, Collier PF. Low mortality rates in industrial cohort studies due to selection for work and survival in the industry. Br J Prev Soc Med 1976;30:225-30.

26. Energy Information Administration, "International energy outlook 2009," Report No. DOE/EIA-0484 (2009), May 2009

27. Antao VC, Petsonk EL, Sokolow LZ, et al. Rapidly progressive coal workers' pneumoconiosis in the United States: geographic clustering and other factors. Occup Environ Med 2005;62:670-4.

28. Laney AS, Petsonk EL, Attfield MD. Pneumoconiosis among underground bituminous coal miners in the United States: is silicosis becoming more frequent? Occup Environ Med 2010;67:652-56.

29. Nikula KJ, Snipes MB, Barr EB, et al. Comparative pulmonary toxicities carcinogenicities of chronically inhaled diesel exhaust and carbon black in F344 rats. Fundam Appl Toxicol 1995:25:80-94. 